\title{
Sorption kinetic study on the removal of phenol using fluted pumpkin and commercial activated carbon
}

\author{
O. A. EKPETE ${ }^{1 *}$, M. HORSFALL JNR ${ }^{2}$ and T. TARAWOU ${ }^{2}$ \\ ${ }^{I}$ Department of Chemistry, Rivers State University of Education, P.M.B 5047 Port Harcourt, Nigeria. \\ Tel: +2348038433325 \\ ${ }^{2}$ Department of Pure and Industrial Chemistry, University of Port Harcourt, P.O.Box.402,Choba,Port- \\ Harcourt, Nigeria. \\ *Corresponding author, E-mail: oekpete@yahoo.com
}

\begin{abstract}
Batch adsorption experiments were performed to study the removal kinetics of phenol from aqueous solution using activated carbon derived from fluted pumpkin stem waste (FAC) and a commercial activated carbon (CAC). Optimum removal of $98.50 \%$ and $98.40 \%$ phenol was achieved at the equilibrium time of 60 mins for FAC and CAC respectively. The applicability of three kinetic models, the pseudo first, pseudo second order and Elovich models for the description of the experimental data was examined. The experimental data was most suitably analysed by the pseudo second order model with a high regression coefficients $\left(\mathrm{R}^{2}\right)$ value for phenol on FAC and CAC as 0.987 and 0.980 respectively. The correlation coefficients followed the order pseudo second order > Elovich kinetic model > pseudo-first order. Fluted pumpkin is the largest consumed vegetable in the West African sub region and therefore, creates one of the major agro waste problems in Nigeria. Preliminary investigations showed that several tons of these waste are produced daily in market places around the country but scarcely useful and therefore create environmental nuisance. The results obtained could be useful for the application of agricultural wastes for phenol removal from industrial wastewater.
\end{abstract}

(C) 2011 International Formulae Group. All rights reserved.

Keywords: Sorption, pollution, agrowaste, activated carbon.

\section{INTRODUCTION}

Phenol and its higher homologues are aromatic molecules that degrade aqueous environments in various ways. The origin is both anthropogenic as well as xenobiotic. Xenobiotic sources are wastes derived from fossil fuel extraction, chemical process industries such as coal, paper, petrochemicals, pharmaceuticals, pesticides and dye manufacturing industries (Kujawski et al., 2004; Entezari et al., 2005). They are considered as one of the priority pollutants in wastewater; because they are harmful to organisms even at low concentrations and many have been classified as hazardous pollutants because of their potential harm to human health. The low volatility of phenol and its affinity to water make oral consumption of contaminated water the greatest risk to humans (Mahvi et al., 2004; Prpich and Daugulis, 2005; Dursun and Kalayei, 2005). 
The ingestion of a small amount of phenol (TLV of 5ppm) by human beings may cause nausea, vomiting, paralysis, coma, greenish or smoky coloured urine and even death from respiratory failure. Fatal poisoning may also occur by adsorption of phenol by skin, if a large area of it is exposed (Banat et al., 2000; Zumiriye and Yener 2001; Banat et al., 2004; Sofia et al., 2005). Wastewater with the highest concentration of phenol $(>100$ $\mathrm{mg} / \mathrm{L}$ ) is typically generated from coke processing Alzaydien and Manasreh (2009). Phenol at a concentration as low as $5.0 \times 10^{-3}$ $\mathrm{mg} / \mathrm{dm}^{-3}$ imparts typical smell upon chlorination and that is why WHO (1984) has prescribed a concentration of $1.0 \times 10^{-3}$ $\mathrm{mg} / \mathrm{dm}^{-3}$ as the guideline concentration for drinking water. Elimination of phenol, thus, is necessity to preserve the environmental quality.

There are many methods to remove phenolic materials from aqueous solutions, e.g., steam distillation and oxidation using a strong oxidizing agent such as hydrogen peroxide. Several decades in the past, extensive research had been conducted to develop innovative and promising adsorbent material for dealing with the treatment problem of contaminated industrial effluents. There is a growing interest in cost effective innovative materials and methods that will be useful in the treatment of industrial waste streams (Horsfall and Spiff, 2004; Okieimen et al., 2007; Ekpete et al., 2010). The study of kinetics in wastewater treatment is significant as it provides valuable insight into the reaction pathways and mechanism of sorption reactions. Kinetics describes the solute uptake rate that controls the residence time of sorbate uptake at the solid -solution interface, and is important to design appropriate sorption treatment plants, and to predict the rate at which any pollutant is removed. The pseudofirst order rate equation of Lagergren has been widely used since 1998. The use of the pseudo - first order and second order kinetics for the sorption of phenol has been reported by (Uddin et al., 2007; Nagda et al., 2007). The objective of this study was to carry out comparative investigation on the kinetics of phenol sorption using activated carbon derived from fluted pumpkin stem waste and a commercial activated carbon as sorbent. Also to test the suitability of pseudo- first order, pseudo-second order and Elovich kinetic models for the adsorption process.

\section{MATERIALS AND METHODS}

The fluted pumpkin stem waste (Telfairia occidentalis Hook $F$ ) used for this study was obtained from Iwofe market Rumuolumeni Port Harcourt. The stems collected were washed thoroughly with water, cut into smaller bits rinsed with deionised water and air dried, and later oven dried at 105 ${ }^{\circ} \mathrm{C}$ for $10 \mathrm{~h}$. The oven-dried fluted pumpkin was carbonised to obtain the carbonised biomass.

\section{Carbonization}

Carbonisation was carried out in the plant physiology and anatomy laboratory of the University of Port Harcourt, using a muffle furnace (Carbolite Sheffield England LMF4) which allows limited supply of air. Carbonisation was done at $350{ }^{\circ} \mathrm{C}$ for two hours and allowed to cool to room temperature for three hours before activation.

\section{Acid activation of the biomass}

A carefully weighed $25.00 \pm 0.01 \mathrm{~g}$ carbonized fluted pumpkin was placed in a beaker containing $500 \mathrm{~cm}^{3}$ of $0.3 \mathrm{M} \mathrm{H}_{3} \mathrm{PO}_{4}$. The content of the beaker was thoroughly mixed, heated until it formed a paste. The paste was put in a crucible and placed in a furnace which heated to $300{ }^{\circ} \mathrm{C}$ for thirty minutes. The fluted activated carbon was washed free of acid to get a $\mathrm{pH}$ of $6.7 \pm 0.12$. This was allowed to cool, washed with distilled water, oven dried at $105{ }^{\circ} \mathrm{C}$ to constant weight and ground. It was sieved with 
a $106 \mu \mathrm{m}$ mesh to obtain a fine powdered activated carbon which was used for the various experiments. The treatment of the adsorbent with $0.3 \mathrm{M} \mathrm{H}_{3} \mathrm{PO}_{4}$ solution aided in the removal of any debris or soluble bio molecules that might interact with phenol during sorption.

\section{Adsorbate}

The test solutions were prepared by diluting a stock solution of phenol to the desired concentrations. A stock solution was obtained by dissolving $1.0 \mathrm{~g}$ of phenol (obtained from Merck India), in distilled water and diluted to $1000 \mathrm{ml}$. Before mixing the adsorbents, the $\mathrm{pH}$ of each test solution was adjusted to the required value with dilute 0.1 $\mathrm{M} \mathrm{H}_{2} \mathrm{SO}_{4}$ and $0.1 \mathrm{M} \mathrm{NaOH}$ solutions. Serial dilutions of the stock solution were made to obtain specific concentrations required for the adsorption study.

\section{Determination of equilibration time}

$1.0 \mathrm{~g}$ of the activated carbons of $106 \mu \mathrm{m}$ mesh particle size was weighed and introduced into various $100 \mathrm{ml}$ conical flasks. $50 \mathrm{ml}$ of $100 \mathrm{mgl}^{-1}$ concentration of phenol solutions prepared in distilled water from the stock solution was added to the biomass. The $\mathrm{pH}$ of these suspensions was adjusted to 6.0. The flasks were labelled for time interval of 20, 30, 40, 50, 60, 70, 80, 90, 100, 110 and 120 minutes. The flasks were tightly covered with cellophane and shaken for the appropriate time intervals on an electric shaker. The suspensions were filtered through Whatman No 40 filter paper, supernatants obtained were analysed using a Unicom UV-visible spectrophotometer at a wavelength corresponding to the maximum absorbance for phenol solution $\left(\lambda_{\max }=269 \mathrm{~nm}\right)$. Effect of temperature was studied using $100 \mathrm{mg} / \mathrm{l}$ phenol and $1.0 \mathrm{~g}$ adsorbent at $30,40,50{ }^{\circ} \mathrm{C}$. This experiment was performed in duplicates.

\section{Data analysis}

The percent of phenol removed by the commercial activated carbon (CAC) was calculated from the difference between the initial $\left(\mathrm{C}_{\mathrm{o}}\right)$ and equilibrium $\left(\mathrm{C}_{\mathrm{e}}\right)$ adsorbate (Phenol) concentrations, which is given in equation 1.

$\% R=\frac{c_{0}-c_{\varepsilon}}{c_{\alpha}} \times 10 \Omega$

The mass transfer properties of the adsorption of phenol on the fluted and commercial activated carbon were evaluated using different kinetic models. Pseudo -first order, Pseudo second order kinetic model, and Elovich kinetic models.

The linearized form of the Pseudo -first order equation is generally expressed as follows

$\log \left(\mathrm{q}_{\mathrm{e}-\mathrm{q}_{\mathrm{t}}}\right)=\log \mathrm{q}_{\mathrm{e}}-\frac{k_{\mathrm{I}}}{2,30 \mathrm{~s}} \mathrm{t}$

Where $\mathrm{q}_{\mathrm{e}}$ is the amount of phenol adsorbed at equilibrium $(\mathrm{mg} / \mathrm{g}), \mathrm{q}_{\mathrm{t}}$ is the amount of phenol adsorbed at time $\mathrm{t}(\mathrm{mg} / \mathrm{g})$, $\mathrm{K}_{1}$ is the first order rate constant $(\mathrm{g} / \mathrm{mg} / \mathrm{min})$ The straight line plot of $\log \left(\mathrm{q}_{\mathrm{e}}-\mathrm{q}_{\mathrm{t}}\right)$ against time should give a linear relationship from which $\mathrm{K}_{1}$ and $\mathrm{q}_{\mathrm{e}}$ can be calculated from the slope and intercept respectively.

The linearized form of the pseudo secondorder model as expressed by Ho et al. (1995) was used.

$\frac{z}{q_{\tau}}-\frac{1}{h_{c}}+\frac{1}{q_{g}} \mathrm{t}$

Where $\mathrm{K}_{2}$ is the second order rate constant $\left(\mathrm{g} / \mathrm{mg} / \mathrm{min}^{1 / 2}\right) \quad \mathrm{h}_{\mathrm{o}}$ is the initial sorption rate $(\mathrm{mg} / \mathrm{g} / \mathrm{min})$.

$\mathrm{h}_{\mathrm{o}}=\mathrm{k}_{2} \mathrm{q}_{\mathrm{e}}^{2}$.

$\mathrm{K}_{2}$ is the second order rate constant ( $\mathrm{q} / \mathrm{mg} / \mathrm{min}), \mathrm{h}$ is the initial sorption rate ( $\mathrm{mg} / \mathrm{g} / \mathrm{min}) . \mathrm{q}_{\mathrm{e}}$ is the equilibrium adsorption capacity $(\mathrm{mg} / \mathrm{g})$. A plot of $\mathrm{t} / \mathrm{qt}$ versus $\mathrm{t}$ should give a linear relationship if the adsorption follows second order. $\mathrm{q}_{\mathrm{e}}$ and $\mathrm{k}_{2}$ were calculated from the slope and intercept of the plot. 
The Elovich equation is mainly applicable for chemisorptions kinetics. The equation is often valid for systems in which the adsorbing surface is heterogeneous Norooozi et al. (2008).

The Elovich model is generally expressed as

$$
\frac{d a_{t}}{d_{t}}=\alpha e^{-\beta q_{t}}
$$

Integrating the equation for the boundary conditions gives

$$
q_{t}=\frac{1}{\beta} \ln (\alpha \beta)+\frac{1}{\beta} \ln t
$$

Where $\alpha$ is the initial adsorption rate (mg/gmin) and $\beta$ is related to the extent of surface coverage and the activation energy for chemisorption $(\mathrm{g} / \mathrm{mg})$. A plot of $q_{\hbar}$ versus $\ln t$ gives a linear trace with a slope of $(1 / \beta)$ and an intercept of $1 / \beta \ln (\alpha \beta)$.

\section{RESULTS}

\section{Sorption kinetic studies}

In order to investigate the mechanisms of the present biosorption process and the potential rate controlling steps such as mass transport and chemical reaction processes, three kinetic models were applied to analyse experimental data. Consequently, the time dependence of such systems under various process conditions was analysed using the pseudo - first order, pseudo-second order and Elovich kinetic rate expression models.

\section{Pseudo -first order model}

The time dependent experimental data was analysed using the pseudo-first order rate equation of Lagergren. In order to determine the rate constants, the straight line plot of log $\left(\mathrm{q}_{\mathrm{e}}-\mathrm{q}_{\mathrm{t}}\right)$ against time $\mathrm{t}$ was established. The rate constant $\mathrm{k}_{1}$ and the equilibrium adsorption capacity, $\mathrm{q}_{\mathrm{e}}$ were calculated from the slope and intercept of the plot (Figure 2). The pseudo first order rate constant, equilibrium sorption capacity and the regression coefficients are given in Table 2.

\section{Pseudo - second order model}

The pseudo second order kinetic model considers the rate limiting step as the formation of chemisorptive bond involving sharing or exchange of electrons between the sorbate and the sorbent. And that pseudo second order kinetic predicts the behaviour over the whole range of studies supporting a pseudo-second order equation. A plot of $t / q_{e}$ against time $(\mathrm{t})$ was taken and is shown in Figure 3. The pseudo-second order rate constant $\left(\mathrm{K}_{2}\right)$, the correlation coefficient $\left(\mathrm{R}^{2}\right)$, the initial sorption rate $\left(\mathrm{h}_{\mathrm{o}}\right)$ and the equilibrium sorption capacity $\left(\mathrm{q}_{\mathrm{e}}^{2}\right)$ were evaluated from the slope and intercept of the plot in Figure 3 respectively.

Table 1: Physico chemical characterization of FAC and CAC.

\begin{tabular}{lcc}
\hline Property & FAC & CAC \\
\hline $\mathrm{pH}$ & $6.70 \pm 0.02$ & $7.00 \pm 0.01$ \\
$\mathrm{pHpzc}$ & $6.50 \pm 0.02$ & $7.00 \pm 0.01$ \\
Moisture & $19.50 \pm 0.02$ & $16.67 \pm 0.03$ \\
Porosity & $0.89 \pm 0.01$ & $0.77 \pm 0.05$ \\
Iodine & $224.90 \pm 0.50$ & $200.46 \pm 0.30$ \\
Ash\% & $22.38 \pm 0.02$ & $17.10 \pm 0.10$ \\
Volatile & $40.06 \pm 3.22$ & $37.32 \pm 2.02$ \\
Particle density & $3.12 \pm 2.52$ & $3.50 \pm 3.22$ \\
\hline
\end{tabular}


O. A. EKPETE et al. / Int. J. Biol. Chem. Sci. 5(3): 1143-1152, 2011

Table 2: $\mathrm{t}_{\exp }$ values of the various surface properties of FAC and CAC.

\begin{tabular}{|c|c|c|c|c|c|c|}
\hline Property & $\begin{array}{c}\text { Carbon } \\
\text { type }\end{array}$ & Mean & SD & df & $\mathbf{t}$ & Decision \\
\hline \multirow[t]{2}{*}{$\mathrm{pH}$} & FAC & 6.70 & 0.02 & 4 & 74.06 & Significant \\
\hline & $\mathrm{CAC}$ & 7.00 & 0.01 & & & \\
\hline \multirow[t]{2}{*}{ Particle densityg $/ \mathrm{cm}^{3}$} & FAC & 3.12 & 2.52 & 4 & 0.16 & Not significant \\
\hline & $\mathrm{CAC}$ & 3.50 & 3.22 & & & \\
\hline \multirow[t]{2}{*}{ Porosity } & FAC & 0.89 & 0.01 & 4 & 4.13 & Significant \\
\hline & $\mathrm{CAC}$ & 0.77 & 0.05 & & & \\
\hline \multirow[t]{2}{*}{ Moisture \% } & FAC & 19.50 & 0.02 & 4 & 141.5 & Significant \\
\hline & $\mathrm{CAC}$ & 16.67 & 0.02 & & & \\
\hline \multirow[t]{2}{*}{ Ash\% } & FAC & 22.38 & 0.02 & 4 & 91.03 & Significant \\
\hline & CAC & 17.10 & 0.10 & & & \\
\hline \multirow[t]{2}{*}{ Volatile matter $\%$} & FAC & 40.06 & 3.22 & 4 & 1.25 & Not significant \\
\hline & $\mathrm{CAC}$ & 37.32 & 2.02 & & & \\
\hline \multirow[t]{2}{*}{ Iodine number } & FAC & 224.90 & 0.50 & 4 & 72.74 & Significant \\
\hline & $\mathrm{CAC}$ & 200.36 & 0.30 & & & \\
\hline \multirow[t]{2}{*}{ Carboxylic } & FAC & 0.08 & 0.01 & 4 & 317 & Significant \\
\hline & $\mathrm{CAC}$ & 0.12 & 0.02 & & & \\
\hline \multirow[t]{2}{*}{ Phenol } & FAC & 0.23 & 0.03 & 4 & 2.00 & Not significant \\
\hline & $\mathrm{CAC}$ & 0.27 & 0.02 & & & \\
\hline \multirow[t]{2}{*}{ Lactones } & FAC & 1.12 & 0.01 & 4 & 22.20 & Significant \\
\hline & CAC & 0.61 & 0.03 & & & \\
\hline \multirow[t]{2}{*}{ Basic } & FAC & 0.49 & 0.02 & 4 & 300 & Significant \\
\hline & CAC & 0.55 & 0.02 & & & \\
\hline \multirow[t]{2}{*}{ pHpzc } & FAC & 6.50 & 0.02 & 4 & 41.66 & Significant \\
\hline & CAC & 7.00 & 0.01 & & & \\
\hline
\end{tabular}


Table 3: Kinetic parameters for the adsorption of phenol on FAC and CAC

\begin{tabular}{ccccc}
\hline Models & PFAC Coefficients & $\mathbf{R}^{2}$ & PCAC Coefficients & $\mathbf{R}^{2}$ \\
\hline Pseudo -first order & $\mathrm{K}_{1}=0.064 \mathrm{~min}^{-1}$ & 0.944 & $\mathrm{~K}_{1}=2.9 \times 10^{-2} \mathrm{~min}^{-1}$ & 0.904 \\
& $\mathrm{q}_{\mathrm{e}}=45.08 \mathrm{mg} / \mathrm{g}$ & & $\mathrm{q}_{\mathrm{e}}=25.94 \mathrm{mg} / \mathrm{g}$ \\
Pseudo- second order & $\mathrm{K}_{2}=1 . .69 \times 10^{-3} \mathrm{~g} / \mathrm{mg} / \mathrm{min}^{1 / 2}$ & 0.987 & $\mathrm{~K}_{2}=1.9 \times 10^{-4} \mathrm{~g} / \mathrm{mg}^{-\mathrm{min}^{1 / 2}}$ & 0.980 \\
& $\mathrm{q}_{\mathrm{e}}=30.30 \mathrm{mg} / \mathrm{g}$ & & $\mathrm{q}_{\mathrm{e}}=29.41 \mathrm{mg} / \mathrm{g}$ \\
& $\mathrm{h}_{\mathrm{o}}=1.56 \times 10^{-2} \mathrm{mg} / \mathrm{g} / \mathrm{min}$ & & $\mathrm{h}_{\mathrm{o}}=1.67 \times 10^{-2} \mathrm{mg} / \mathrm{g} / \mathrm{min}$ \\
Elovich equation & $\alpha=0.088 \mathrm{mg} / \mathrm{gmin}$, & 0.950 & $\alpha=0.118 \mathrm{mg} / \mathrm{gmin}$, & 0.977 \\
& $\beta=1.58 \mathrm{~g} / \mathrm{mg}$ & & $\beta=2.78 \mathrm{~g} / \mathrm{mg}$ & \\
\hline
\end{tabular}

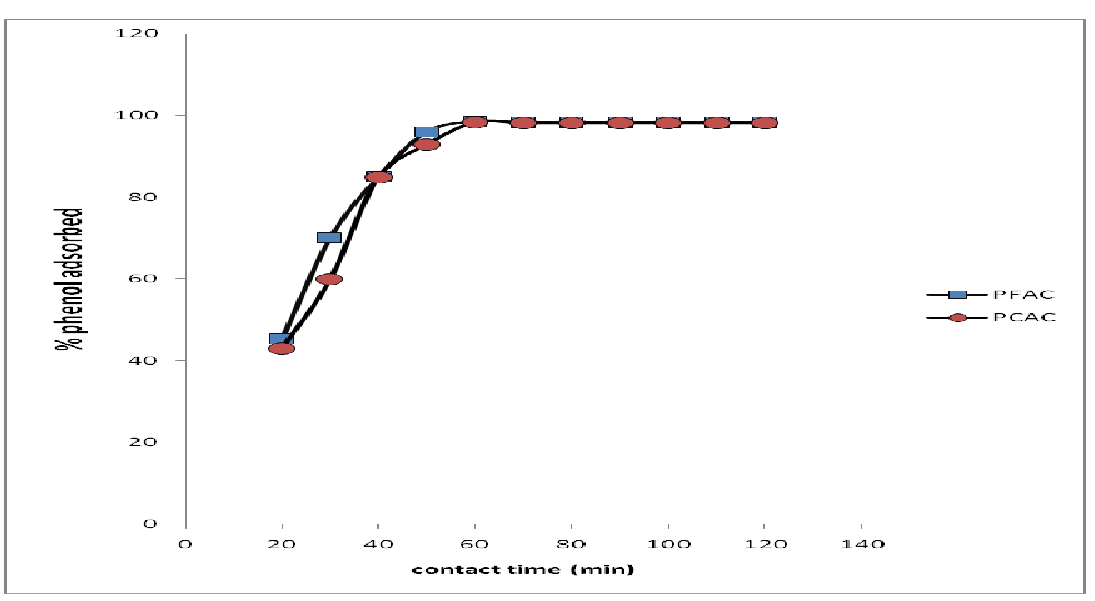

Figure 1: Effect of contact time on the percentage sorption of phenol on to FAC and CAC 
O. A. EKPETE et al. / Int. J. Biol. Chem. Sci. 5(3): 1143-1152, 2011

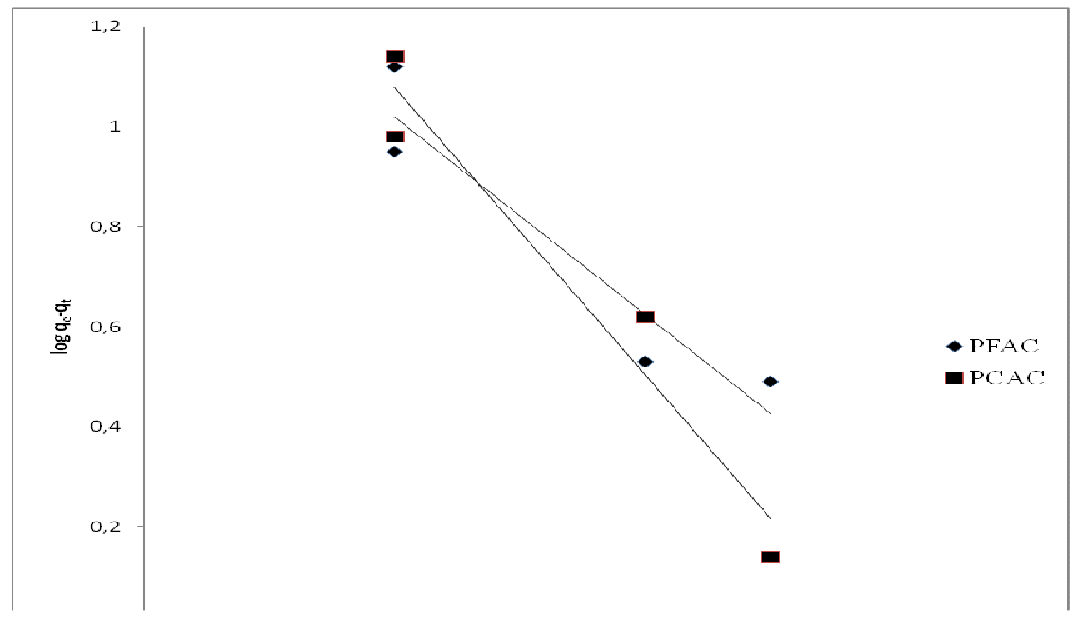

Figure 2: Plots of pseudo first order kinetic model of phenol on to FAC and CAC

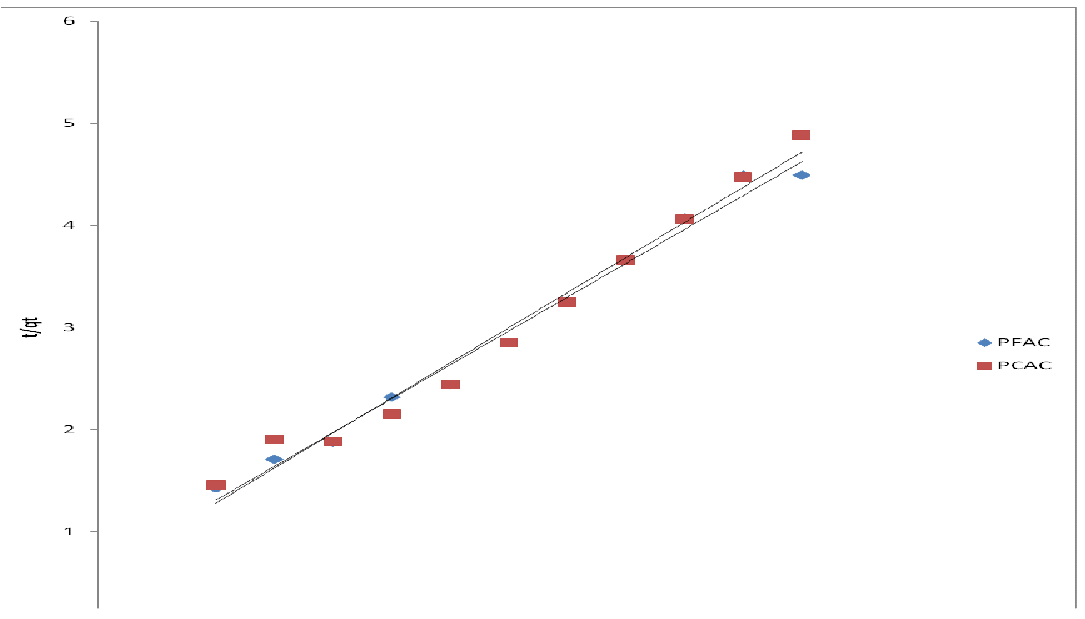

Figure 3: Plots of pseudo-second order sorption kinetics of phenol on to FAC and CAC

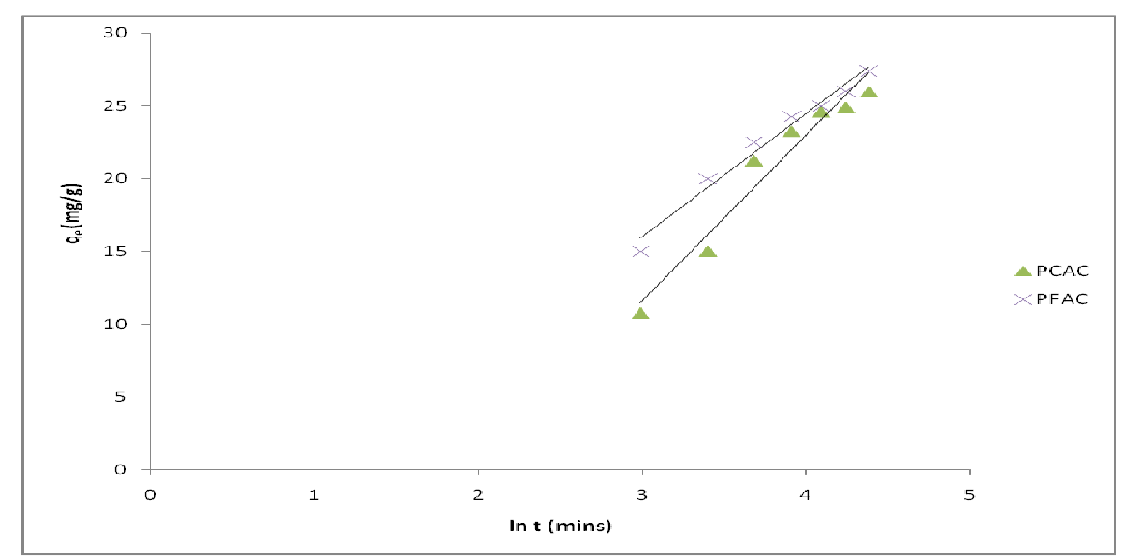

Figure 4: Plots of Elovich sorption kinetics of phenol on to FAC and CAC. 


\section{DISCUSSION}

Proximate analysis

The analysis (Table 1) showed a low amount of moisture, ash and volatile matter, indicating that the particle density is relatively small and that the biomaterial should be an excellent raw material for adsorbents to be used in column or fixed -bed reactors. $\mathrm{pH}$ values of the activated carbon sample are therefore within the specified range of activated carbon 6-8. The porosity and iodine number is comparably to other materials used for batch analysis (Horsfall et al., 2003, Tarawou and Horsfall 2007; Ekpete et al., 2010).

\section{Student's t-test analyses}

The surface properties of the activated carbon derived from fluted pumpkin stem waste was compared with those of commercial activated carbon. The values of statistical t-test analyses carried out to determine if there was any significant difference between the properties obtained for the FAC and CAC at 5\% level of significance and calculated $t_{\exp }$ values are given in Table 2.

From Table 2 it was found that, the activated carbon samples, $t_{\exp }<D F$ for the following properties, volatile matter, phenol content of the activated carbons and particle density. This shows that there is no significant difference between the mean values of volatile matter, phenol content and particle density, of the activated carbon samples derived from fluted and commercial activated carbon. There is a significant difference in the properties of moisture, $\mathrm{pH}$, porosity, ash content, iodine number, carboxylic acid content, lactones, pHpzc and basic sites content of the activated carbons. In spite of the significant differences that existed for most of the surface properties between the commercial and fluted activated carbons, the activated carbons were very efficient and effective in the removal of phenol and chlorophenol from solution showing that, though surface properties of adsorbents play significant role in sorption, such properties also depends on the method and conditions of activation which may therefore not be the sole determining factor for adsorption as illustrated in this study.

\section{Effect of contact time}

As can be seen from Figure 1, the adsorption of phenol exhibits saturation kinetic as the quantity of bound phenolic ions stagnates after approximately 60 minutes for the fluted and commercial activated carbon, meaning that the possibility of further adsorption is very small. The higher sorption rate at the initial period may be due to an increased number of vacant sites on the adsorbent available at the initial stage (Vadivelan and Kumar 2005; Uddin et al., 2007). The decrease in the adsorption of phenol with time could be due to the accumulation of phenol particles in the vacant sites leading to a decrease in sorption percent at time 70-120 minutes. The reduction in the percentage of phenol removed as a result of increased contact time was not significant, since more than $98 \%$ of phenol was removed even at contact time of 120 minutes.

\section{Kinetic models determination}

Linear plots of all considered kinetic models and the adsorption kinetic rate constants are shown in Figures 2-4 and Table 3 respectively. All kinetic models show good correlation values. As shown in Table 3, the equilibrium sorption capacity $\left(\mathrm{q}_{\mathrm{e}}\right)$ obtained from the pseudo-first order linear plot of phenol on FAC was $45.08 \mathrm{mg} / \mathrm{g}$ better than $\mathrm{q}_{\mathrm{e}}$ of phenol on CAC $25.94 \mathrm{mg} / \mathrm{g}$. It was also observed that the pseudo first order rate constant $K_{1}$ and regression coefficient $R_{1}^{2}$ for phenol on FAC was (0.064 $\mathrm{min}^{-1}$ and 0.944$)$ greater than that of phenol on CAC $(0.029$ $\mathrm{min}^{-1}$ and 0.94 ) respectively. The pseudo second order model suitably describe the kinetic data as presented in Table 3 with higher regression values $(0.987$ and 0.980$)$ for both phenol on FAC and CAC respectively. This suggests that the pseudo second order adsorption mechanism was predominant and that the overall rate of the phenol adsorption 
process appeared to be controlled by chemical process as similar results were obtained by (Sarkar et al., 2003; Vadivelan and Kumar 2005; Uddin et al., 2007).

The results of Elovich plot for the adsorption of phenol on FAC and CAC is shown in Figure 4. The Elovich equation which has been shown to be useful in describing chemisorptions on highly heterogeneous adsorbents, gives a good account of the adsorption of phenol. From the result it was observed that the initial sorption rate, $\alpha$, and the desorption rate $\beta$ was higher for PCAC $0.118 \mathrm{mg} / \mathrm{gmin}$ and $2.78 \mathrm{~g} / \mathrm{mg}$ compared to PFAC with $\alpha 0.888 \mathrm{~g} / \mathrm{min}$ and $\beta$ $1.58 \mathrm{~g} / \mathrm{mg}$ respectively. Since adsorption and desorption are interrelated in surface transport, we observe a linear relationship between, $\alpha$ and $\beta$ as presented in Table 3. The Elovich model was found to be adequate to satisfactorily explain the present biosorption phenomenon with correlation values of 0.977 and 0.950 for PCAC and PFAC, which consolidate the chemisorption hypothesis (Ho, 2006).

\section{Conclusion}

The study demonstrates that fluted pumpkin stem waste could be used as a novel raw material for the production of activated carbon. The fluted activated carbon compared favourably to the commercial activated carbon. Adsorption kinetic study regression values followed the order pseudo second order $>$ Elovich > pseudo first order with higher regression values for phenol on FAC.

\section{ACKNOWLEDGEMENTS}

This research was conducted as a part of Ph.D dissertation in the Department of Pure and Industrial Chemistry in the University of Port Harcourt. The authors are grateful to $\mathrm{S}$. K. Harry of the Department of Mathematics for his assistance in this work.

\section{REFERENCES}

Alzaydien AS, Manasreh W. 2009. Equilibrium kinetic and thermodynamic studies on the adsorption of phenol onto activated phosphate rock. Int. J. Phy. Sci., 4(4): 172-181.

Banat FA, Al-Bashir B, Al-Asheh S, Hayajneh O. 2000. Adsorption of phenol by bentonite. Environmental Pollution, 107: 391-398.

Banat FA, Al-Asheh S, Al-Makhadmeh L. 2004. Utilization of raw and activated date pits for the removal of phenol from aqueous solutions. Chem. Eng. Technol., 27: $80-86$.

Dursun A, Kalayei S. 2005. Equilibrium, kinetic and thermodynamic studies on adsorption of phenol onto chitin. $J$. hazardous. Materials., 123: 151-157.

Ekpete OA, Sor EN, Ogiga E, Amadi JN. 2010. Adsorption of $\mathrm{Pb}^{2+}$ and $\mathrm{Cu}^{2+}$ ions from aqueous solutions by mango tree (Mangifera indica) sawdust. Int. J. Biol. Chem. Sci., 4(5): 1410-1416.

Entezari M, Petrier P, Devidal P. 2005. Sonochemical degradation of phenol in water a comparison of classical equipment with a new cylindrical reactor. Ultra Son. Sonochem., 10: 103108.

Ho YS, John WD, Foster CF. 1995. Batch Nickel removal from aqueous solution by Sphagnum moss peat. Wat. Res,. 29 (5): 1327-1332.

Ho YS. 2006. Second order kinetic model for the sorption of cadmium onto tree fern: A comparism of linear and non-linear methods. Water Res.,40: 199.

Horsfall MJnr, Abia AA, Spiff IA. 2003. A removal of $\mathrm{Cu}^{2+}$ and $\mathrm{Zn}^{2+}$ ions from wastewater by cassava (Manichol esculentus cranz) Waste Biomass. African Journal Biotechnology, 2: 969976.

Horsfall MJnr, Spiff AI. 2004. Equilibrium study of $\mathrm{Al}^{3+}, \mathrm{Co}^{2+}$ and $\mathrm{Ag}^{+}$in aqueous solutions by fluted pumpkin (Telfairia occidentalis Hook $F$ ) waste biomass. Acta Chim. Slov., 18: 85-96.

Kujawski WA, Warzawsk T, Ratajczak T, Porebski W, Zostraws C. 2004. Sep purify. Technol., 40: 123-134. 
Lagergren S. 1998. Zur theorie der sogenannten adsorption geloster stoffe. Kungliga Svenska Veten Kapsakadmiens Handlinger, 24: 1-13.

Mahvi A, Maleki A, Eslami A. 2004. Potential of rice husk and rice husk ash for phenol removal in aqueous systems. American Journal Applied Sciences, 1(4): 321-326.

Nagda G, Diwan M, Ghole S. 2007. Potential of Tendu leaves refuse for phenol removal in aqueous systems. Applied Ecology Environmental Research, 5(2): 1-9.

Norooozi B, Sorial GA, Bahrami H, Aram M. 2008. Turkish J. Eng. Envi. Sci.,143

Okieimen F, Okieimen C, Wuana A. 2007. Preparation and characterization of activated carbon from rice husk. J. Chem. Soc. Nigeria, 32: 126-136

Prpich G, Daugulis A. 2005. Enhanced biodegradation of phenol by a microbial consortium in a solid liquid two phase partitioning bioreactor. Biodegradation, 16: 329-339.

Sarkar M, Acharya KP, Bhattacharya B. 2003. Modelling the adsorption kinetics of some priority organic pollutants in water from diffusion and energy parameters.
Journal Colloid Interface Science, 266: 28-32.

Sofia A, Tzayhiri G, Guillermo O, Madel S, Brenda P. 2005. Adsorption of phenol and chlorophenol from aqueous solutions by porous clay heterostructure (PCH). J. Mex Chem. Soc., 49(3): 287- 291.

Tarawou T, Horsfall M Jnr, Vicente JL. 2007. Adsorption of methyl red by water hyacinth (eichornia crassipes) Biomass. Chemistry \& Biodiversity., 4: 2236-2245.

Uddin M, Islam M, Abedin M. 2007. Adsorption of phenol from aqueous solution by water hyacinth. ARPN Journal of Engineering and Applied Sciences, 2: 11-16.

Vadivelan V, Kumar KV. 2005. Equilibrium, Kinetics, Mechanism, and process design for the sorption of methylene blue onto rice husk. Journal Colloid and Interface Science, 286: 90-100.

World Health Organization. 1984. Guidelines for Drinking Water Quality (Vol 1). World Health Organization: Geneva; 85.

Zumiriye A, Yener J. 2001. A comparative adsorption/bio sorption study of monochlorinated phenols onto various sorbents. Waste Management, 21: 695701. 